\title{
Impact of White Matter Lesions on Cognition in Stroke Patients Free from Pre-Stroke Cognitive Impairment: A One-Year Follow-Up Study
}

\author{
Hege Ihle-Hansen ${ }^{\mathrm{a}}$ Bente Thommessen ${ }^{\mathrm{b}}$ \\ Morten Wang Fagerland ${ }^{c}$ Torgeir Bruun Wyller ${ }^{d}$ \\ Knut Engedal $^{\mathrm{d}}$ Anne Rita Øksengård ${ }^{\text {h }}$ Vidar Stenset $^{\mathrm{e}}$ \\ Kirsti Løken ${ }^{f}$ Brynjar Fure ${ }^{g}$ \\ ${ }^{a}$ Department of Geriatric Medicine, Bærum Hospital, Vestre Viken Hospital Trust, \\ Rud, ' Department of Neurology, Akershus University Hospital, Lørenskog, ' Unit of \\ Biostatistics and Epidemiology, Oslo University Hospital, d Department of Geriatric \\ Medicine, Oslo University Hospital, e Department of Neurosurgery, Oslo University Hospital, \\ ${ }^{f}$ Curato, and ${ }^{9}$ Norwegian Knowledge Centre for the Health Services, Oslo, Norway; \\ ${ }^{\mathrm{h}}$ Karolinska Institute, NVS, Department of Clinical Geriatrics, Karolinska University Hospital, \\ Huddinge, Sweden
}

\section{Key Words}

Stroke $\cdot$ Cognitive impairment $\cdot$ Cerebrovascular diseases $\cdot$ Degenerative diseases $\cdot$ White matter lesions

\begin{abstract}
Background/Aim: Post-stroke cognitive impairment and dementia may be caused by pure vascular, pure degenerative or mixed disease. The relation between post-stroke cognitive impairment and the combination of vascular pathology and degenerative changes is less evaluated. We aimed to evaluate the associations between white matter lesions (WMLs) and patient performance 1 year after stroke on tests of executive functioning, memory and visuospatial function, adjusted for the effects of lifestyle and disease-related factors, including medial temporal lobe atrophy (MTLA). Methods: Patients with a first-ever stroke or transient ischemic attack were invited to participate in the study. The associations between the cognitive test performances and WMLs were studied using linear regression [Trail Making Test B (TMT B) and 10word test] and logistic regression (Clock Drawing Test). Results: In total, 199 patients completed the follow-up. The TMT B $(p=0.029)$ and the 10 -word test $(p=0.014)$ were significantly associated with WMLs; however, the Clock Drawing Test $(p=0.19)$ was not. The TMT $B(p=0.018)$ and


the 10-word test ( $p \leq 0.001$ ) were both significantly associated with MTLA. Conclusion: Impaired executive functioning and memory are significantly associated with WMLs and MTLA. The mechanisms explaining post-stroke cognitive impairment are multifactorial, including different types of vascular pathology and coexisting vascular and degenerative changes.

Copyright $\odot 2012$ S. Karger AG, Base

\section{Introduction}

Stroke is associated with an increased risk of cognitive impairment and dementia $[1,2]$ and contributes to cognitive decline in various neurodegenerative dementia disorders [3]. Post-stroke cognitive impairment and dementia may be caused by pure vascular disease, pure degenerative disease or the coexistence of vascular and degenerative diseases [4]. In addition to evident stroke lesions, post-stroke vascular changes include subcortical white matter lesions (WMLs), silent lacunar infarctions and cerebral microhemorrhages [5]. WMLs, initially described in 1987 [6] and named leukoaraiosis [7], are defined as areas of high signal intensity on $\mathrm{T}_{2}$-weighted magnetic resonance imaging (MRI) and are related to variable degrees of demyelination, axonal loss and gliosis [8].

WMLs are associated with vascular risk factors, especially hypertension and higher age [9]. Further, WMLs are associated with the development of vascular and mixed dementia in patients with mild cognitive impairment [10]. Elderly patients with severe WMLs are at risk of becoming more dependent in activities of daily living [11]. Severe post-stroke WMLs predict cognitive decline [12] and indicate a higher risk of recurrent stroke [13]. WMLs are present in 11-21\% of adults aged around 64 years [14], in up to $44 \%$ of patients with stroke or transient ischemic attack (TIA) and in $50-75 \%$ of patients with vascular dementia [15].

Executive and visuospatial dysfunctions are associated with severe WMLs, whereas memory and language dysfunctions are only weakly associated with WMLs [16, 17]. However, the correlation between specific clinical symptoms and the topographical location of WMLs is under debate $[18,19]$. The relation between post-stroke cognitive impairment and the combination of vascular pathology and degenerative changes has not been fully examined.

Accordingly, we aimed to evaluate the associations between WMLs and patient performance 1 year after stroke on tests measuring executive functioning, memory and visuospatial function. Results were adjusted for the possible effects of lifestyle and disease-related factors, including medial temporal lobe atrophy (MTLA) as an indicator of possible neurodegenerative disease mechanisms.

\section{Methods}

\section{Participants}

All patients with a first-ever stroke or TIA admitted to the Stroke Unit of Bærum Hospital, Vestre Viken Hospital Trust between February 2007 and July 2008 were invited to participate in the study. Only those patients who survived the acute phase the first week were assessed. The hospital has a policy of admitting all stroke patients directly to the Stroke Unit. It serves two counties with a total population of approximately 160,000 inhabitants.

We excluded patients with subarachnoid hemorrhage, dementia or mild cognitive impairment diagnosed before stroke onset, a history of cognitive decline or cognitive decline as indicated by a score of $\geq 3.7$ on the Informant Questionnaire on Cognitive Decline in the 
Elderly (IQ-CODE) [20], previous stroke or TIA, patients who did not speak Norwegian and patients with a remaining life expectancy of less than 1 year as estimated by the treating physician. The IQ-CODE was filled in by the patient's spouse, a first-degree relative or a close friend. The cut off 3.7 was chosen based on the results of a previous study that reported prestroke cognitive decline with an IQ-CODE score of $\geq 4.0$ [21] and modified to ensure exclusion of pre-stroke dementia.

\section{Assessments}

The primary distinction between ischemic stroke and hemorrhagic stroke was based on neuroimaging with cerebral computer tomography (CT). We used the WHO definition of stroke and the clinical diagnosis of TIA based on the acute loss of focal cerebral function with symptoms lasting less than $24 \mathrm{~h}$ [22]. TIA patients were included since cognitive impairments in TIA patients may persist beyond the resolution of focal symptoms [23].

Cognitive functioning was measured at baseline and after 12 months using the MiniMental State Examination (MMSE) [24], the Clock Drawing Test [25], the Trail Making Test A and B (TMT A and B) [26] and the 10-word test including delayed recall from the Repeatable Battery for the Assessment of Neuropsychological Status (RBANS) (maximal score 40) [27]. The Clock Drawing Test was dichotomized into correct or incorrect answers ( 5 vs. $\leq 4$ according to Shulman [25]). The TMT B was interrupted after $5 \mathrm{~min}$, but we allowed the patients to continue afterwards if they insisted. All patients tried to perform all tests, including the TMT A and TMT B, in the acute phase, but results are only reported from those who were able to complete the tests.

The cognitive assessments were chosen in order to evaluate different cognitive domains. The 10-word test is a measure of memory impairment. The Clock Drawing Test primarily measures visuospatial functions, while the TMT B measures executive functioning. Cognitive impairment of subcortical vascular origin has traditionally been strongly associated with impaired executive functioning, while cognitive impairment of cortical, degenerative origin more often affects episodic memory, visuospatial function and praxis. Although single tests may measure more than one specific cognitive function, we chose a test battery that could assess different cognitive domains.

Neurological impairment was assessed using the National Institutes of Health Stroke Scale (NIHSS) [28]. The neurological examinations were performed on the first day after admittance by an experienced stroke physician. The NIHSS was repeated at discharge and at the 12-month follow-up. We screened for pre-stroke cognitive impairment using the 26-question version of the IQ-CODE [20], repeated after 12 months. Activities of daily living were assessed by the Barthel ADL index [29], and global functioning was evaluated by the modified Rankin Scale [29]. Patients with ischemic stroke were classified according to The Trial of Org 10172 in Acute Stroke Treatment (TOAST) classification [30] by a stroke physician.

Patients underwent an MRI of the brain at the 12-month follow-up. Cerebral atrophy was measured according to the method first described by Scheltens et al. [31]. Based on the height of the hippocampal formation and the enlargement of the surrounding cerebrospinal fluid spaces, the MTLA is graded from 0 to 4 (MTLA grade $0=$ no atrophy; MTLA $4=$ highest degree of atrophy; MTLA 0-1 are considered normal values).

WMLs were quantified with a semi-automated method in the Nordic lCE Basis Module as described earlier [32]. The manual placement of regions of interest in known white matter fiber tracks is a common method to measure diffusion parameters. This software is preferred for this purpose, but other programs for diffusion tensor imaging are available [33]. In the fluid-attenuated inversion recovery images, pixel values in the white matter higher than $2 \mathrm{SD}$ above the mean pixel value of the respective slices were defined as WMLs. The total WML areas in all slices were added together and multiplied with the slice thickness to obtain the 
total WML volume $(\mathrm{ml})$. In this sample, patients with pencil line lesions along the ventricles and non-confluent small subcortical lesions did not have a total WML volume exceeding 1.5 $\mathrm{ml}$. Moderate and severe lesions may represent subcortical ischemic small vessel disease [16].

\section{Statistics}

The associations between the cognitive test performances (outcome variables) and WMLs (explanatory variable) were studied using linear regression (TMT B and 10-word test) and logistic regression (Clock Drawing Test). First, univariate analyses were performed. Second, 19 candidate variables were analyzed as possible confounding variables, i.e. age, sex, Apo E alleles, MTLA, education, vascular risk factors, etiological subtypes of ischemic stroke, neurological deficits as measured by NIHSS and stroke in the left hemisphere (table 2). Only predictors assessed at baseline, except for physical activity which was assessed at the followup, were included in the analyses in order to evaluate the effect on cognitive outcomes, WMLs and MTLA 12 month after stroke. All explanatory variables with a p value $<0.20$ in unadjusted analyses were included in the multivariate regression models. All variables (except for WMLs) with a p value $>0.05$ were thereafter removed from the models, one at a time, until the final adjusted models were reached. We assessed the interaction between WMLs and MTLA for each outcome using regression models that included WMLs, MTLA and their product as explanatory variables. We used all data available for each analysis, which ranged from $\mathrm{n}=148$ in multivariable analyses to $\mathrm{n}=197$ in univariable analyses.

Statistical analyses were performed with STATA 11. All significance tests were twotailed and performed at the $5 \%$ level.

\section{Ethics}

The study was approved by the Regional Committee for Ethics in Medical Research and by the Data Protection Authorities. All patients gave their written informed consent before inclusion. First-degree relatives gave consent on behalf of patients with reduced capacity. This procedure was approved by the Ethics Committee.

\section{Results}

\section{Baseline Characteristics}

After inviting 253 patients, 250 agreed to participate in the study. Of these, 23 were excluded; 12 did not fulfill the inclusion criteria ( 6 had an IQ-CODE score $\geq 3.7,1$ did not speak Norwegian, 1 had an infarction in the spinal cord, 1 had suffered a previous TIA, 2 withdrew their consent and 1 patient died before signing the consent) and 11 patients were diagnosed with other disease than stroke.

Of the 227 remaining patients, 174 (76.7\%) had a cerebral infarction, 36 (15.8\%) had suffered a TIA and 17 (7.5\%) were diagnosed with cerebral hemorrhage. Baseline characteristics are listed in table 1.

In total, 199 patients completed the follow-up. Of the 28 patients missing, 19 died and 9 refused to complete the follow-up period. Further, 182 had an MRI for analysis of WMLs and MTLA.

The estimated associations between WMLs and the tests for different cognitive domains, including the potentially confounding variables, are displayed in table 2 . The cognitive tests for executive functioning, memory and visuospatial function after 1 year of follow-up were all significantly associated with the degree of WMLs. After fitting multivariable regression models including patients' characteristics, vascular risk factors and stroke characteristics, the associations remained statistically significant between the severity of WMLs and the 
Table 1. Patients characteristics at baseline and 12 months

\begin{tabular}{|c|c|c|}
\hline Variable & $\begin{array}{l}\text { Baseline } \\
(\mathrm{n}=227)\end{array}$ & $\begin{array}{l}12 \text { months } \\
(\mathrm{n}=199)\end{array}$ \\
\hline \multicolumn{3}{|l|}{ Demographics } \\
\hline Male gender & $115(50.7)$ & \\
\hline Age, years & $72.7 \pm 12.2$ & \\
\hline Education $<9$ years & $55(24.2)$ & \\
\hline \multicolumn{3}{|l|}{ Stroke subtype } \\
\hline Cerebral infarction & $174(76.7)$ & \\
\hline TIA & $36(15.9)$ & \\
\hline Cerebral hemorrhage & $17(7.5)$ & \\
\hline \multicolumn{3}{|l|}{ Risk factors } \\
\hline Hypertension & $135(59.5)$ & \\
\hline Hyperlipidemia & $124(54.6)$ & \\
\hline Diabetes & $27(11.9)$ & \\
\hline Cigarette smoking (present) & $51(22.5)$ & \\
\hline Coronary heart disease & $53(23.3)$ & \\
\hline Atrial fibrillation & $75(33.0)$ & \\
\hline $\mathrm{BMI}>25$ & $126(55.5)$ & \\
\hline \multicolumn{3}{|l|}{ TOAST classification } \\
\hline Large vessel disease & $24(11.4)$ & \\
\hline Cardioembolic disease & $66(31.4)$ & \\
\hline Small vessel disease & $66(31.4)$ & \\
\hline Stroke of undetermined etiology & $54(25.7)$ & \\
\hline \multicolumn{3}{|l|}{ Topography } \\
\hline Right hemisphere & $85(37.4)$ & \\
\hline Left hemisphere & $115(50.7)$ & \\
\hline Cerebellum/brain stem & $27(11.9)$ & \\
\hline \multicolumn{3}{|l|}{ Assessments } \\
\hline NIHSS score on day 1 & $4.1(1.0-5.0)$ & \\
\hline NIHSS score at discharge & $2.4(0-2.0)$ & $1.8(0-1.0)$ \\
\hline BI score & $20.0(18.0-20.0)$ & $18.6(19.0-20.0)$ \\
\hline mRS score & $1.0(0-2.0)$ & $1.3(1.0-2.0)$ \\
\hline \multicolumn{3}{|l|}{ Cognitive assessments ( $n$ ) } \\
\hline IQ-CODE & $3.10 \pm 0.23(224)$ & $3.31 \pm 0.41(188)$ \\
\hline MMSE & $25.66 \pm 4.78(214)$ & $25.86 \pm 5.8(194)$ \\
\hline TMT A & $74.5 \pm 65.0(192)$ & $63.3 \pm 48.9(185)$ \\
\hline TMT B & $157.4 \pm 94.5(162)$ & $142.4 \pm 86.7(160)$ \\
\hline 10 word-test, immediate recall & $21.2 \pm 7.1(203)$ & $23.6 \pm 8.5(195)$ \\
\hline 10 word-test, delayed recall & $4.2 \pm 2.5(201)^{*}$ & $5.0 \pm 3.1(195)$ \\
\hline
\end{tabular}

Values denote $\mathrm{n}(\%)$, median (IQR) or mean \pm SD.

Hyperlipidemia $=$ Total cholesterol $>5 \mathrm{mmol} / \mathrm{l}$ or low-density lipoprotein cholesterol $>3 \mathrm{mmol} / \mathrm{l}$; Coronary heart disease $=$ previous myocardial infarction or present angina pectoris; $\mathrm{BMI}=$ body mass index; IQR = interquartile range; $\mathrm{BI}=$ Barthel activities of daily living index; $\mathrm{mRS}=$ modified Rankin Scale.

* 15 patients did not complete the delayed recall. This test was introduced a little later in the study. 
Table 2. Results of unadjusted and adjusted regression models for all proposed explanatory variables and the three outcomes

\begin{tabular}{|c|c|c|c|c|c|c|c|c|c|c|c|c|}
\hline \multirow[t]{3}{*}{ Variable } & \multicolumn{4}{|l|}{10 -word test } & \multicolumn{4}{|l|}{ TMT B } & \multicolumn{4}{|c|}{ Clock Drawing Test } \\
\hline & \multicolumn{2}{|l|}{ unadjusted } & \multicolumn{2}{|l|}{$\begin{array}{l}\text { adjusted } \\
\text { (final model) }\end{array}$} & \multicolumn{2}{|l|}{ unadjusted } & \multicolumn{2}{|c|}{$\begin{array}{l}\text { adjusted } \\
\text { (final model) }\end{array}$} & \multicolumn{2}{|l|}{ unadjusted } & \multicolumn{2}{|l|}{$\begin{array}{l}\text { adjusted } \\
\text { (final model) }\end{array}$} \\
\hline & $\begin{array}{l}\text { regression } \\
\text { coefficients } \\
(95 \% \mathrm{CI})\end{array}$ & $\mathrm{p}$ value & $\begin{array}{l}\text { regression } \\
\text { coefficients } \\
(95 \% \mathrm{CI})\end{array}$ & $\mathrm{p}$ value & $\begin{array}{l}\text { regression } \\
\text { coefficients } \\
(95 \% \mathrm{CI})\end{array}$ & $\mathrm{p}$ value & $\begin{array}{l}\text { regression } \\
\text { coefficients } \\
(95 \% \mathrm{CI})\end{array}$ & $\mathrm{p}$ value & $\begin{array}{l}\text { OR estimate } \\
(95 \% \mathrm{CI})\end{array}$ & $\mathrm{p}$ value & $\begin{array}{l}\text { OR estimate } \\
(95 \% \mathrm{CI})\end{array}$ & $\begin{array}{l}\mathrm{p} \\
\text { value }\end{array}$ \\
\hline WMLs & $\begin{array}{l}-0.30 \\
(-0.44,-0.17)\end{array}$ & $<0.001$ & $\begin{array}{l}-0.16 \\
(-0.28,-0.03)\end{array}$ & 0.014 & $\begin{array}{l}3.50 \\
(1.83,5.18)\end{array}$ & $<0.001$ & $\begin{array}{l}1.75 \\
(0.18,3.33)\end{array}$ & 0.029 & $\begin{array}{l}1.06 \\
(1.02,1.10)\end{array}$ & 0.003 & $\begin{array}{l}1.03 \\
(0.99,1.07)\end{array}$ & 0.19 \\
\hline Age & $\begin{array}{l}-0.24 \\
(-0.33,-0.14)\end{array}$ & $<0.001$ & & & $\begin{array}{l}2.82 \\
(1.80,3.84)\end{array}$ & $<0.001$ & $\begin{array}{l}2.09 \\
(0.94,3.23)\end{array}$ & $<0.001$ & $\begin{array}{l}1.06 \\
(1.03,1.09)\end{array}$ & $<0.001$ & $\begin{array}{l}1.06 \\
(1.02,1.10)\end{array}$ & 0.001 \\
\hline $\begin{array}{l}\text { Sex } \\
(\text { male }=0)\end{array}$ & $\begin{array}{l}-1.17 \\
(-3.59,1.25)\end{array}$ & 0.34 & & & $\begin{array}{l}6.12 \\
(-21.5,33.7)\end{array}$ & 0.66 & & & $\begin{array}{l}3.59 \\
(1.97,6.55)\end{array}$ & $<0.001$ & $\begin{array}{l}3.26 \\
(1.62,6.55) \\
\end{array}$ & 0.001 \\
\hline $\begin{array}{l}\text { Number of Apo E } 4 \\
\text { alleles present }\end{array}$ & overall: $\mathrm{p}$ & 0.72 & & & overall: $\mathrm{p}$ & $=0.10$ & & & overall: $\mathrm{p}$ & $=0.62$ & & \\
\hline 1 vs. 0 & $\begin{array}{l}-0.85 \\
(-3.80,2.11)\end{array}$ & 0.57 & & & $\begin{array}{l}-36.7 \\
(-71.3,-2.10)\end{array}$ & 0.038 & & & $\begin{array}{l}0.01 \\
(-0.16,0.18)\end{array}$ & 0.89 & & \\
\hline 2 vs. 0 & $\begin{array}{l}2.05 \\
(-5.49,9.60)\end{array}$ & 0.59 & & & $\begin{array}{l}-27.3 \\
(-114,59.1)\end{array}$ & 0.53 & & & $\begin{array}{l}0.22 \\
(-0.22,0.66)\end{array}$ & 0.33 & & \\
\hline $\begin{array}{l}\text { MTLA } \\
\text { (2-4 vs. } 0-1)\end{array}$ & $\begin{array}{l}-6.26 \\
(-8.50,-4.02)\end{array}$ & $<0.001$ & $\begin{array}{l}-4.51 \\
(-6.67,-2.35)\end{array}$ & $<0.001$ & $\begin{array}{l}70.9 \\
(44.3,97.5)\end{array}$ & $<0.001$ & $\begin{array}{l}33.0 \\
(5.86,60.1)\end{array}$ & 0.018 & $\begin{array}{l}3.76 \\
(1.96,7.22) \\
\end{array}$ & $<0.001$ & & \\
\hline $\begin{array}{l}\text { Education } \\
(\leq 9 \text { years }=0)\end{array}$ & $\begin{array}{l}6.55 \\
(3.73,9.37) \\
\end{array}$ & $<0.001$ & $\begin{array}{l}4.83 \\
(2.32,7.34) \\
\end{array}$ & $<0.001$ & $\begin{array}{l}-22.3 \\
(-57.5,12.8)\end{array}$ & 0.21 & & & $\begin{array}{l}0.58 \\
(0.29,1.16)\end{array}$ & 0.12 & & \\
\hline $\begin{array}{l}\text { Homocysteine } \\
(\mu \mathrm{mol} / \mathrm{l})\end{array}$ & $\begin{array}{l}-0.25 \\
(-0.50,-0.009)\end{array}$ & 0.042 & & & $\begin{array}{l}2.45 \\
(-0.41,5.32)\end{array}$ & 0.093 & & & $\begin{array}{l}1.01 \\
(0.95,1.07)\end{array}$ & 0.82 & & \\
\hline $\begin{array}{l}\text { Hypertension } \\
\text { (treated) }\end{array}$ & $\begin{array}{l}-3.07 \\
(-5.51,-0.63)\end{array}$ & 0.014 & & & $\begin{array}{l}30.7 \\
(3.52,57.9) \\
\end{array}$ & 0.027 & & & $\begin{array}{l}1.65 \\
(0.91,2.99)\end{array}$ & 0.10 & & \\
\hline Hyperlipidemia & $\begin{array}{l}4.57 \\
(2.22,6.92) \\
\end{array}$ & $<0.001$ & $\begin{array}{l}2.72 \\
(0.59,4.85)\end{array}$ & 0.013 & $\begin{array}{l}-38.3 \\
(-65.5,-11.2)\end{array}$ & 0.006 & & & $\begin{array}{l}0.82 \\
(0.46,1.45)\end{array}$ & 0.49 & & \\
\hline Diabetes & $\begin{array}{l}-3.84 \\
(-7.63,-0.06)\end{array}$ & 0.047 & & & $\begin{array}{l}63.7 \\
(14.9,112)\end{array}$ & 0.011 & $\begin{array}{l}60.4 \\
(17.2,104)\end{array}$ & 0.006 & $\begin{array}{l}1.61 \\
(0.66,3.92)\end{array}$ & 0.29 & & \\
\hline $\begin{array}{l}\text { Atrial fibrillation } \\
\text { (at present) }\end{array}$ & $\begin{array}{l}-1.11 \\
(-3.80,1.57)\end{array}$ & 0.41 & & & $\begin{array}{l}17.1 \\
(-13.0,47.2)\end{array}$ & 0.26 & & & $\begin{array}{l}1.00 \\
(0.54,1.88)\end{array}$ & 0.99 & & \\
\hline $\begin{array}{l}\text { Coronary heart } \\
\text { disease }\end{array}$ & $\begin{array}{l}-2.23 \\
(-5.06,0.61)\end{array}$ & 0.12 & & & $\begin{array}{l}45.5 \\
(13.7,77.3)\end{array}$ & 0.005 & & & $\begin{array}{l}0.86 \\
(0.44,1.71)\end{array}$ & 0.68 & & \\
\hline $\begin{array}{l}\text { Cigarette } \\
\text { smoking (at } \\
\text { present) }\end{array}$ & $\begin{array}{l}-0.14 \\
(-3.54,3.26)\end{array}$ & 0.94 & & & $\begin{array}{l}-5.65 \\
(-45.1,33.8)\end{array}$ & 0.78 & & & $\begin{array}{l}0.83 \\
(0.36,1.90)\end{array}$ & 0.65 & & \\
\hline BMI & $\begin{array}{l}0.20 \\
(-0.11,0.51)\end{array}$ & 0.21 & & & $\begin{array}{l}-1.47 \\
(-5.22,2.29)\end{array}$ & 0.44 & & & $\begin{array}{l}0.91 \\
(0.84,0.98)\end{array}$ & 0.018 & & \\
\hline $\begin{array}{l}\text { Physical activity } \\
\text { (min/week) }\end{array}$ & $\begin{array}{l}0.007 \\
(0.001,0.01)\end{array}$ & 0.017 & & & $\begin{array}{l}-0.035 \\
(-0.10,0.03)\end{array}$ & 0.27 & & & $\begin{array}{l}0.997 \\
(0.995,0.999)\end{array}$ & 0.007 & & \\
\hline Diagnosis & overall: $\mathrm{p}=$ & 0.010 & & & overall: $\mathrm{p}$ & $=0.53$ & & & overall: $\mathrm{p}$ & $=0.13$ & & \\
\hline $\begin{array}{l}\text { TIA vs. } \\
\text { infarction }\end{array}$ & $\begin{array}{l}3.63 \\
(0.36,6.90)\end{array}$ & 0.030 & & & $\begin{array}{l}-20.7 \\
(-57.3,15.9)\end{array}$ & 0.27 & & & $\begin{array}{l}0.40 \\
(0.16,0.98)\end{array}$ & 0.046 & & \\
\hline $\begin{array}{l}\text { Hemorrhage } \\
\text { vs. infarction }\end{array}$ & $\begin{array}{l}-3.93 \\
(-8.17,0.31)\end{array}$ & 0.069 & & & $\begin{array}{l}0.78 \\
(-53.4,54.9)\end{array}$ & 0.98 & & & $\begin{array}{l}0.71 \\
(0.25,2.03)\end{array}$ & 0.53 & & \\
\hline $\begin{array}{l}\text { TOAST }(\text { small } \\
\text { vessel disease }=0)\end{array}$ & $\begin{array}{l}-2.05 \\
(-4.67,0.56)\end{array}$ & 0.12 & & & $\begin{array}{l}30.7 \\
(2.20,59.2) \\
\end{array}$ & 0.035 & $\begin{array}{l}32.9 \\
(7.69,58.0)\end{array}$ & 0.011 & $\begin{array}{l}1.15 \\
(0.61,2.15)\end{array}$ & 0.67 & & \\
\hline $\begin{array}{l}\text { NIHSS (score on } \\
\text { day 1) }\end{array}$ & $\begin{array}{l}-0.62 \\
(-0.85,-0.38)\end{array}$ & $<0.001$ & $\begin{array}{l}-0.28 \\
(-0.53,-0.04)\end{array}$ & 0.017 & $\begin{array}{l}5.33 \\
(0.54,10.1)\end{array}$ & 0.029 & $\begin{array}{l}5.63 \\
(1.02,10.2)\end{array}$ & 0.017 & $\begin{array}{l}1.15 \\
(1.07,1.23)\end{array}$ & $<0.001$ & $\begin{array}{l}1.12 \\
(1.04,1.22)\end{array}$ & 0.005 \\
\hline $\begin{array}{l}\text { Topographic } \\
\text { location }(\text { left }=0)\end{array}$ & $\begin{array}{l}3.06 \\
(0.68,5.44)\end{array}$ & 0.012 & $\begin{array}{l}2.59 \\
(0.58,4.59)\end{array}$ & 0.009 & $\begin{array}{l}-9.21 \\
(-36.4,18.0)\end{array}$ & 0.50 & & & $\begin{array}{l}1.00 \\
(0.56,1.77)\end{array}$ & 1.00 & & \\
\hline
\end{tabular}

Apo $\mathrm{E}=$ Apolipoprotein E; Hyperlipidemia $=$ total cholesterol $>5 \mathrm{mmol} / \mathrm{l}$ or low-density lipoprotein cholesterol $>3 \mathrm{mmol} / \mathrm{l}$; Coronary heart disease $=$ previous myocardial infarction or present angina pectoris; BMI = body mass index. The values are the regression coefficients for the 10-word test and TMT B (linear regression) and the odds ratio for the Clock Drawing Test (logistic regression).

performances on TMT B ( $\mathrm{p}=0.029)$ and the 10-word list with immediate recall $(\mathrm{p}=0.014)$, but not between WMLs and the Clock Drawing Test $(\mathrm{p}=0.19)$ (table 2).

In addition, age $(\mathrm{p}<0.001)$, MTLA $(\mathrm{p}=0.018)$, diabetes $(\mathrm{p}=0.006)$, NIHSS score on day $1(p=0.017)$ and small vessel disease as cause of the stroke $(p=0.011)$ were significantly and independently associated with the TMT B, whereas low education $(\mathrm{p}<0.001)$, MTLA $(\mathrm{p}<$ $0.001)$, hyperlipidemia $(\mathrm{p}=0.011)$, NIHSS score on day $1(\mathrm{p}=0.023)$ and left hemisphere 
stroke $(\mathrm{p}=0.012)$ were significantly and independently associated with the 10 -word test. Failure on the Clock Drawing Test was significantly associated with increasing age ( $\mathrm{p}=$ $0.001)$, NIHSS score on day $1(\mathrm{p}=0.005)$ and female sex $(\mathrm{p}=0.001)$.

No interaction between WMLs and MTLA was observed for any of the three outcomes (all $\mathrm{p} \geq 0.34$ ), indicating that different processes are involved in atrophy and chronic vascular changes.

\section{Discussion}

We found that the cognitive tests for both executive functioning (TMT B) and impaired memory (10-word test) were significantly associated with WMLs. However, the bivariate association between the Clock Drawing Test and WMLs was not statistically significant after adjusting for the influence of increasing age, NIHSS score on day 1 and gender.

The association between deficits in executive functioning and WMLs in stroke patients has been reported earlier $[16,17]$ and may be due to chronic cerebral small vessel disease with endothelial dysfunction, hypoperfusion and affected blood-brain barrier leading to subsequent cell injury $[34,35]$. Furthermore, our results also indicate an association between impaired memory and WMLs after stroke. This contrasts the traditional belief that memory disturbances are less severe in vascular dementia than in Alzheimer's disease [36]. Previous findings regarding non-memory-related cognitive deficits in association with WMLs diverge even more [19], and in stroke patients, impaired memory has been related to reduced temporal lobe functioning [37]. However, vascular changes in the brain can be associated with executive functioning as well as with impaired memory [14,38], ostensibly due to subcortical damage and a disruption of the pathways between gray and white matter. WMLs are related to more rapid global functional decline [39] and, in the post-stroke situation, may contribute to cognitive decline and progression of cognitive dysfunction. In addition, we observed an association between reduced performance on the 10-word test and stroke in the left hemisphere, indicating cortical damage affecting language and understanding.

Both reduced executive functioning and impaired memory were significantly associated with MTLA, supporting the theory that a degenerative component plays a central role in some patients with post-stroke cognitive impairments [3]. Vascular lesions may amplify the effect of existing degenerative pathology or affect beta-amyloid deposits. Further, MTLA, in addition to subcortical vascular changes, seems strongly related to post-stroke executive dysfunction. Our findings support the assumption that white matter changes, vascular lesions of the brain and Alzheimer's disease pathology coexist and give rise to an increased risk of post-stroke cognitive impairment $[13,40]$.

We observed an association between some vascular risk factors and cognitive impairment; hyperlipidemia was associated with the 10-word test and diabetes with the TMT B. Midlife high cholesterol increases the risk of Alzheimer's disease later in life [41], represents a well-known risk for vascular disease [42] and may indicate a risk for post-stroke cognitive impairments of both degenerative and vascular origin, whereas diabetes is one of the traditional risks for lacunar infarcts [43].

Surprisingly, hypertension was not associated with any of the cognitive tests. Midlife hypertension is a risk factor for dementia [41] as well as for WMLs [9]. One explanation for our finding may be that we only identified treated hypertension, and the hypertension in our patients was mostly well controlled before the stroke. Treatment of vascular risk factors in patients with cerebrovascular disease may slow the progression of WMLs [44] and, therefore, intensive secondary prevention may contribute to preserve cognitive functioning. 
Our study has some limitations. We included patients with TIA, and both the incidence of cognitive impairment and the WML load are lower in these patients. Limitations also include the absence of a measure of silent infarcts, microbleeds and global cortical atrophy. In addition, WMLs were measured only in volume. A more precise topographical description of the lesions could have been even more helpful in understanding the relationship between WMLs and cognitive functioning.

We found that the cognitive tests for both executive functioning (TMT B) and impaired memory (10-word test) were significantly associated with WMLs. There was also a significant association between impaired executive functioning and memory with MTLA. Our findings support the assumption that the mechanisms explaining post-stroke cognitive impairment are multifactorial, including different types of vascular pathology and coexistence of vascular and degenerative changes. The relationship between WMLs and MTLA was not significant.

Clinically, it is of importance to determine which patients are at risk of dementia among those who survive a stroke. The onset of cognitive impairment may be linked to the initial severity of WMLs as well as the pre-stroke degenerative process. This aspect has clinical implications in choosing the most appropriate therapeutic strategy and to start prevention earlier in order to preserve cognition. Treatment requires control of all modifiable risk factors.

\section{Acknowledgments}

The authors' work has been supported by Helse Sør-Øst RHF and Vestre Viken Hospital Trust. We want to thank the patients participating in the study as well as colleagues, physiotherapists and occupational therapists at our hospital. We are indebted to the clinical research nurses Nadine Prost, Anne Wergeland and Anne-Mette Brenden and our secretary Kari Wie Skar for excellent assistance. Thanks to Sarah Kristine Kaldestad for English proofreading.

\section{Disclosure Statement}

The authors have no conflict of interest.

\section{References}

-1 Ivan CS, Seshadri S, Beiser A, Au R, Kase CS, Kelly-Hayes M, et al: Dementia after stroke: the Framingham Study. Stroke 2004;35:1264-1268.

-2 Pendlebury ST, Rothwell PM: Prevalence, incidence, and factors associated with pre-stroke and poststroke dementia: a systematic review and meta-analysis. Lancet Neurol 2009;8:1006-1018.

-3 O’Brien JT, Erkinjuntti T, Reisberg B, Roman G, Sawada T, Pantoni L, et al: Vascular cognitive impairment. Lancet Neurol 2003;2:89-98.

-4 Leys D, Hénon H, Mackowiak-Cordoliani MA, Pasquier F. Poststroke dementia. Lancet Neurol 2005; 4:752-759.

-5 Viswanathan A, Rocca WA, Tzourio C: Vascular risk factors and dementia: how to move forward? Neurology 2009;72:368-374.

-6 Fazekas F, Chawluk JB, Alavi A, Hurtig HI, Zimmerman RA: MR signal abnormalities at $1.5 \mathrm{~T}$ in Alzheimer's dementia and normal aging. AJR Am J Roentgenol 1987;149:351-356.

7 Hachinski VC, Potter P, Merskey H: Leuko-araiosis. Arch Neurol 1987;44:21-23. 
-8 Frisoni GB, Galluzzi S, Pantoni L, Filippi M: The effect of white matter lesions on cognition in the elderly - small but detectable. Nat Clin Pract Neurol 2007;3:620-627.

-9 de Leeuw FE, de Groot JC, Oudkerk M, Witteman JC, Hofman A, van GJ, et al: A follow-up study of blood pressure and cerebral white matter lesions. Ann Neurol 1999;46:827-833.

-10 Bombois S, Debette S, Bruandet A, Delbeuck X, Delmaire C, Leys D, et al: Vascular subcortical hyperintensities predict conversion to vascular and mixed dementia in MCI patients. Stroke 2008;39: 2046-2051.

-11 Inzitari D, Simoni M, Pracucci G, Poggesi A, Basile AM, Chabriat H, et al: Risk of rapid global functional decline in elderly patients with severe cerebral age-related white matter changes: the LADIS study. Arch Intern Med 2007;167:81-88.

-12 Dufouil C, Godin O, Chalmers J, Coskun O, MacMahon S, Tzourio-Mazoyer N, et al: Severe cerebral white matter hyperintensities predict severe cognitive decline in patients with cerebrovascular disease history. Stroke 2009;40:2219-2221.

-13 Leys D, Hénon H, Pasquier F: White matter changes and poststroke dementia. Dement Geriatr Cogn Disord 1998;9(suppl 1):25-29.

14 Debette S, Markus HS: The clinical importance of white matter hyperintensities on brain magnetic resonance imaging: systematic review and meta-analysis. BMJ 2010;341:c3666.

-15 Leys D, Englund E, Del ST, Inzitari D, Fazekas F, Bornstein N, et al: White matter changes in stroke patients. Relationship with stroke subtype and outcome. Eur Neurol 1999;42:67-75.

-16 de Groot JC, de Leeuw FE, Oudkerk M, van GJ, Hofman A, Jolles J, et al: Cerebral white matter lesions and cognitive function: the Rotterdam Scan Study. Ann Neurol 2000;47:145-151.

-17 Price CC, Jefferson AL, Merino JG, Heilman KM, Libon DJ: Subcortical vascular dementia: integrating neuropsychological and neuroradiologic data. Neurology 2005;65:376-382.

-18 Pantoni L, Gorelick P: Advances in vascular cognitive impairment 2010. Stroke 2011;42:291-293.

-19 Gorelick PB, Scuteri A, Black SE, DeCarli C, Greenberg SM, Iadecola C, et al: Vascular contributions to cognitive impairment and dementia: a statement for healthcare professionals from the American Heart Association/American Stroke Association. Stroke 2011;42:2672-2713.

-20 Jorm AF, Jacomb PA: The Informant Questionnaire on Cognitive Decline in the Elderly (IQCODE): socio-demographic correlates, reliability, validity and some norms. Psychol Med 1989;19:1015-1022.

-21 Hénon H, Durieu I, Lebert F, Pasquier F, Leys D: Influence of prestroke dementia on early and delayed mortality in stroke patients. J Neurol 2003;250:10-16.

-22 A classification and outline of cerebrovascular diseases. II. Stroke 1975;6:564-616.

23 Pendlebury ST, Wadling S, Silver LE, Mehta Z, Rothwell PM: Transient cognitive impairment in TIA and minor stroke. Stroke 2011;42:3116-3121.

-24 Folstein MF, Folstein SE, McHugh PR: 'Mini-mental state'. A practical method for grading the cognitive state of patients for the clinician. J Psychiatr Res 1975;12:189-198.

-25 Shulman KI: Clock-drawing: is it the ideal cognitive screening test? Int J Geriatr Psychiatry 2000;15: $548-561$.

-26 Reitan RM: Validity of the trail making test as an indicator of organic brain damage. Percept Mot Skills 1958;8:271-276.

-27 Randolph C, Tierney MC, Mohr E, Chase TN: The Repeatable Battery for the Assessment of Neuropsychological Status (RBANS): preliminary clinical validity. J Clin Exp Neuropsychol 1998;20:310-319.

-28 Goldstein LB, Bertels C, Davis JN: Interrater reliability of the NIH stroke scale. Arch Neurol 1989; 46:660-662.

-29 Sulter G, Steen C, De KJ: Use of the Barthel index and modified Rankin scale in acute stroke trials. Stroke 1999;30:1538-1541.

-30 Adams HP Jr, Bendixen BH, Kappelle LJ, Biller J, Love BB, Gordon DL, et al: Classification of subtype of acute ischemic stroke. Definitions for use in a multicenter clinical trial. TOAST. Trial of Org 10172 in Acute Stroke Treatment. Stroke 1993;24:35-41.

- 31 Scheltens P, Leys D, Barkhof F, Huglo D, Weinstein HC, Vermersch P, et al: Atrophy of medial temporal lobes on MRI in 'probable' Alzheimer's disease and normal ageing: diagnostic value and neuropsychological correlates. J Neurol Neurosurg Psychiatry 1992;55:967-972.

-32 Stenset V, Bjornerud A, Fjell AM, Walhovd KB, Hofoss D, Due-Tonnessen P, et al: Cingulum fiber diffusivity and CSF T-tau in patients with subjective and mild cognitive impairment. Neurobiol Aging 2011;32:581-589. 
33 Zhang Y, Schuff N, Jahng GH, Bayne W, Mori S, Schad L, et al: Diffusion tensor imaging of cingulum fibers in mild cognitive impairment and Alzheimer disease. Neurology 2007;68:13-19.

- 34 Faraci FM: Protecting against vascular disease in brain. Am J Physiol Heart Circ Physiol 2011; 300:H1566-H1582.

- 35 Grinberg LT, Thal DR: Vascular pathology in the aged human brain. Acta Neuropathol 2010;119: $277-290$.

-36 Roman GC, Erkinjuntti T, Wallin A, Pantoni L, Chui HC: Subcortical ischaemic vascular dementia. Lancet Neurol 2002;1:426-436.

-37 Snaphaan L, Rijpkema M, van Uden I, Fernández G, de Leeuw FE: Reduced medial temporal lobe functionality in stroke patients: a functional magnetic resonance imaging study. Brain 2009;132: $1882-1888$.

- 38 Stenset V, Hofoss D, Berstad AE, Negaard A, Gjerstad L, Fladby T: White matter lesion subtypes and cognitive deficits in patients with memory impairment. Dement Geriatr Cogn Disord 2008;26:424431.

39 Inzitari D, Pracucci G, Poggesi A, Carlucci G, Barkhof F, Chabriat H, et al: Changes in white matter as determinant of global functional decline in older independent outpatients: three year follow-up of LADIS (leukoaraiosis and disability) study cohort. BMJ 2009;339:b2477.

40 Hachinski V: Shifts in thinking about dementia. JAMA 2008;300:2172-2173.

-41 Kivipelto M, Helkala EL, Laakso MP, Hanninen T, Hallikainen M, Alhainen K, et al: Midlife vascular risk factors and Alzheimer's disease in later life: longitudinal, population based study. BMJ 2001; 322:1447-1451.

-42 Kannel WB, McGee D, Gordon T: A general cardiovascular risk profile: the Framingham Study. Am J Cardiol 1976;38:46-51.

43 Arboix A, Marti-Vilalta JL: Lacunar stroke. Expert Rev Neurother 2009;9:179-196.

-44 Richard E, Gouw AA, Scheltens P, van Gool WA: Vascular care in patients with Alzheimer disease with cerebrovascular lesions slows progression of white matter lesions on MRI: the evaluation of vascular care in Alzheimer's disease (EVA) study. Stroke 2010;41:554-556. 